\title{
Teaching Reform of Applied Undergraduate Computer Basic Courses Based on Skills, Application and Innovation
}

\author{
Nan $\mathrm{Xie}^{1, \mathrm{a}^{*}}$, Liru Han ${ }^{1, \mathrm{a}}$, Daqing $\mathrm{Li}^{1, \text { a }}$ and Saiqu $\mathrm{Lu}^{1, \mathrm{a}}$ \\ ${ }^{1}$ Information Engineering and Art \& Design College, Zhejiang University of Water Resources and \\ Electric Power, Hangzhou 310018, China. \\ a595075251@qq.com \\ *The corresponding author
}

\begin{abstract}
Keywords: Applied undergraduate; Technical innovation; Application practice; Public computer
\end{abstract} basic courses

\begin{abstract}
The purpose of training applied undergraduate colleges and public computer course teaching program as the leading factor, the teaching members do some teaching reform in public computer basic courses of undergraduate non computer majors. The ways of implementation mainly include setting up the students as the new teaching concept, the application and the cultivation of innovative consciousness, constructing the teaching system integrating outstanding skills and practical. Also, the teaching members design courses' teaching modular tasks based on CDIO engineering practice mode, and expand the rich second classroom for students through multi-link innovation teaching (classroom + Network + community + knowledge skills competition). Lastly, three-in-one curriculum evaluation mode based on knowledge, skills and attitude has been done in students. Through two teaching period, it is proved that the teaching effect and teaching quality have been changed significantly by the teaching reform and exploration.
\end{abstract}

\section{Introduction}

Most college non computer major students have set up two public computer courses, which is mainly to train students to use computer technology to solve practical problems. Compared with the theoretical nature of the traditional curriculum, these courses are highly practical, requiring students to master theoretical knowledge, but also to master the operational skills and be able to apply in practice. If teachers are lack of good teaching methods in teaching organization, do not pay attention to the cultivation of autonomous learning and innovation ability of students, would be out of line with practice, serious sound teaching effect. Faced with this situation, we need to find a suitable teaching mode in the practice, in the teaching reform for the implementation of better ways to stimulate students' interest, improve teaching effectiveness [1-3]. And application type undergraduate colleges pay more attention to the cultivation of students' skills in innovation and application ability, how to let the students through the study of these basic courses, master some basic theory to solve practical problems, the course of the teaching team of corresponding teaching reform and teaching practice.

\section{Teaching Implementation Means}

Setting up the New Teaching Idea. Firstly, we should establish a new teaching idea which makes student oriented, application oriented, to cultivate the innovation consciousness, and change the teacher as the center into the student-centered from the classroom as center to turning for multi-link innovation teaching environment, and so on.

The students are mainly engineering students. From the perspective of "knowledge, skills, attitudes, application, innovation", the teaching members establish three levels structure about public computer basic education curriculum system. And the principle is paying attention to basic teaching and strengthening students' practice in order to cultivate students' comprehensive ability [4-5]. 
The first level is the skill level. It mainly includes the college computer fundamentals course. Through the course study and experiment, the students have the ability to skillfully operate computer skills and information processing in the network environment.

The second level is the technical level. It includes database application technology course, VB or C language program design course and the corresponding training course.

The third level is development layer. Combined with the professional, the college opens a lot of computer application technology as the foundation and combining with leading edge technology development of elective courses, such as multimedia technology and application, web art design and production, website development, computer image processing course.

The students are from different regions of different learning conditions and family environment and their computer basis are not the same. Therefore, students can take elective courses according to personal conditions and interests, and they stress the required credits rather than compulsory courses. The principle of the three levels is to strengthen the foundation, to highlight the personality, flexible teaching, to cultivate the sense of innovation.

Break the Old Teaching Positioning. In the light of applied undergraduate colleges teaching target and personnel training goal, we should change the Zhejiang province computer rank examination syllabus as the main teaching goal and teaching position starting from zero. But the actual needs of the enterprises and institutions from investigation and analysis are mainly oriented to application, and highlight the practical ability and the ability of culture. The teaching positioning is been made up of non-zero point positioning, facing the practical application, taking the demand as the guidance, highlighting the applied undergraduate professional, personalized and innovative talents training, and so on.

Building a New Teaching System Based on "Skill, Practice and Application". According to the new teaching orientation and teaching principles, we have done some teaching design of substantial reform on the part of the public computer basic courses. Abandon traditional instructional design that teachers have make the knowledge into level progressive teaching system, and use a series practical and typical simulation cases. We can construct a new teaching system based on the integration of achieving outstanding skills, closing to the practice and learning to practice. The main contents are shown as follows.

Selecting the Teaching Focus and Constructing a New Content System. We visited a lot of enterprises and institutions, and we found that the most demand in the basic application of computer is using a computer to solve a variety of complex office information $[1,6,8]$. Therefore, from the practical application, we have screened four main teaching focuses about the basic computer course.

Selecting the Simulation Case and Constructing a New Teaching Layout Task Driven Centered. We have to do to cover the specific teaching content of the new teaching system, the key lies in the selection of cases. We have selected a series of simulation teaching cases according to the actual work and the actual demand of the enterprise, realized the knowledge of the case group coverage, to construct the teaching layout. The simulation teaching case design not only takes into account the practicality and interest, but also gives attention to the logic of knowledge. To make the students feel the real needs of the real work, and fully stimulate the students' learning motivation.

At the same time, we divide the design of the case into two levels: basic requirements and high-level requirements, in order to meet the needs of sub level teaching. After completing each case designing, students should be summed up, and the new requirements given by the teachers to give material, after class by the students to complete the login teaching web site. This method has greatly improved the enthusiasm of students' Autonomous learning. Students have the problem to learn, so that students really become the main body of the teaching process. Many students put forward their own solutions to the problem, showing a high capacity for innovation.

Extending the Classroom Teaching, Guiding the Students to Learn Independently and Cultivating the Students' Innovation Sense. The curriculum teaching practice adopts the teaching organization form that the level is progressive, the lesson inside and outside the class, the course teaching content is divided into four parts: basic knowledge, main content, comprehensive operation 
and innovative design. The first and the fourth part of the students through the teaching website of self-study completed, second and third in part by the teachers in the classroom teaching, so that to achieve the classroom teaching extends to outside.

In order to explore the problems to guide and maintain learners reflect stresses the teaching theory of "learning interest and motivation" teaching ideas; increase the "innovative design" link in the curriculum organization. Innovative design for students drew up several alternative projects [5-9]. The aim is to cast a brick to attract jade, guide the student to carry on the creative learning. Innovative design activities including the "computer application ability and information literacy competition", "Yang youth style - the vitality of development branch tundra activities game", "five water co governance" t-shirt design competition, "hung wing DreamWorks resume making competition", "snag stripping like cup" and some animation design contest and other activities, through the campus activities to fully mobilize the enthusiasm of students, expand the classroom teaching, enrich the spare time life of our students.

Carrying on the Curriculum Modular and the Project Teaching Design Based on the CDIO Project Mode. Teaching reform of the course mainly to project as the carrier of CDIO teaching idea of public computer basic courses of teaching design and implementation, ability training into classroom teaching, cultivate students' comprehensive professional ability and comprehensive quality. Teaching process always take ability as the standard, students centered "teaching principles, public computer basic course were project modular decomposition, used in the form of team cooperation, relying on the project will be the key ability of students training into courses teaching, change the past knowledge to master for the main line of classroom teaching design. Teachers from knowledge, teaching organization leaders change become a learning process consultation, guidance and partners. And the students will be the main body of teaching, in order to achieve the overall culture and the development of students' comprehensive ability [7-8, 10].

CDIO mode is a kind of teaching project from project conception, design, implementation and operation of the process, through the design and the process of practice, students can apply knowledge organically. Through the implementation of each stage of the project, cultivate students' ability. The teaching practice process has been divided into six parts, and it is simply shown as Fig. 1.

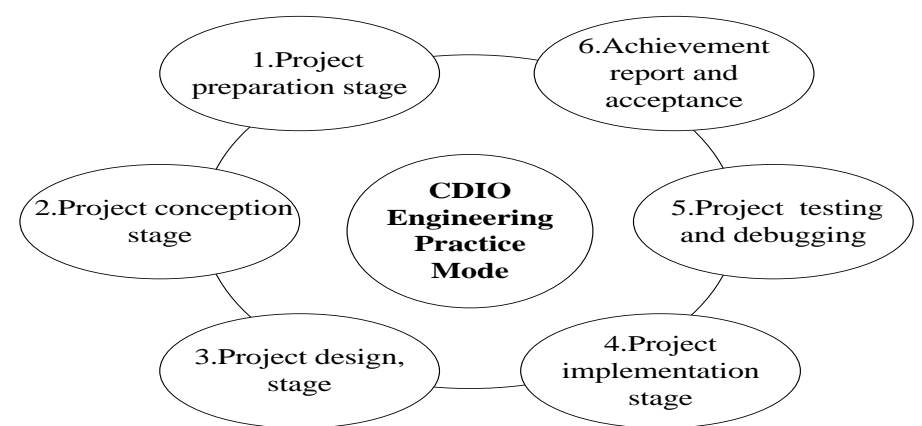

Figure 1. Teaching practice process based on CDIO

\section{Implementation of the "Knowledge, Skills and Attitudes" Three-In-One Curriculum Evaluation}

Thoroughly and implemented the school to "knowledge, skill, attitude" Trinity curriculum assessment management approach, compared with the traditional usually scores and the final exam scores a certain proportion of assessment mechanism, it more conducive to the cultivation of students' innovation ability, practical skills, solve practical problems of flexible application ability. Based on CDIO teaching process and the appraisal way throughout the entire project development and implementation process, students will do the main project conception and design show evaluation and project implementation process evaluation, the project report and defense, student self-evaluation and mutual evaluation, the evaluation of teachers and enterprise engineer[3-4,10]. 
The examination content has: 1) knowledge (40\%), it includes professional knowledge and general knowledge; 2) abilities (50\%). It is divided into professional ability and general ability. And the professional ability mainly reflects the students to complete the project with professional skills, such as project development, design and construction, strong innovation ability. The general ability mainly reflects the students' social adaptability and occupation career promotion, such as learning ability, teamwork ability, communication skills and language ability; 3) attitude (10\%). It mainly reflects in the occupation morals and the enthusiasm of learning, the evaluation methods for students to have a positive, enthusiastic, preserve attitude to acquire more knowledge and skills.

\section{Conclusion}

For teachers, teaching method, teaching method, teaching as well. The application type undergraduate nonpublic computer basic course of computer specialty teaching reform and practice, change the old teaching mode, establish new teaching ideas, skills to application of innovative practice as the main line of the design of teaching, combined with the actual situation of students, continue to explore research, looking for new effective teaching methods and means, using the comprehensive evaluation the students, to cultivate students' autonomous learning interest, improve students' practical ability, and constantly improve the quality of teaching, the teaching reform and practice of teaching two periods, students' autonomous learning and learning interest is greatly improved, to achieve the purpose of certain teaching reform.

\section{Acknowledgements}

This work was supported by Zhejiang Key Discipline of Instrument Science \& Technology.

\section{References}

[1]. Jin Jian, Fan Yanghui. Discussion on the teaching reform of computer basic courses in applied undergraduate colleges [J]. Computer Era, 2016(03): pp. 72-74.

[2]. Li Jiang, Zhang Xiaodan. Application of Computer Culture Foundation Curriculum reform based on B-learning [J]. Fujian Computer, 2015(04):pp. 60-61.

[3]. Xu Min. Problems and solutions in the teaching of computer basic knowledge in Colleges and Universities [J]. China Educational Technology \& Equipment, 2014(24): pp. 112-113.

[4]. Zhang Junling, Liu Hongbo. the Educational Reform on the Curriculum of Computer Basic Course in University [J]. Heilongjiang Science and Technology Information, 2014(04) : pp.126

[5]. Lu Hanquan, He Qinming, Xu Jingchun. Design of teaching content of "University Computer Foundation" based on Computational Thinking [J]. China University Teaching, 2012(09) : pp.55-58.

[6]. Cao RAN, Zhao Jie. Existing problems in university computer basis teaching and solutions [J]. Journal of Nanchang College of Education, 2011(12): pp. 47-48.

[7]. Wang Nan. Reflections on the teaching reform of College Computer Basic Education [J]. Journal of Inner Mongolia Normal University (Education Science), 2010(01) : pp. 154-156.

[8]. Zou Xian chun, Zhang Xiaoli, Li Shengyu. An Innovation and Practice by Classificationand Hierarchical Division of the Basic ComputerCourse Teaching Based on the Network Environment $[\mathrm{J}]$. Journal of Southwest China Normal University (Natural Science Edition), 2010(06): pp.213-218. 
[9]. Liu Shuting, Wang Liansheng, Liu Duanduan. Teaching Reform and Exploration on the Computer Basic courses in Non-computer Speciality [J]. Research and Exploration in Laboratory, 2009(11) : pp.126-128

[10]. Computer Basic Courses Network Learning Platform. HTTP://WEB.ZJWEU.EDU.CN 